\title{
The Importance of Gender as a Moderator for the Relationship between Emotional Intelligence and Mental Health of Adolescents
}

\author{
Jafar Shabani (Corresponding author) \\ Department of management, Aliabad Katoul Branch, Islamic Azad University, Aliabad Katoul, Iran \\ E-mail: jshabani@yahoo.com
}

Alireza Jilardi Damavandi

Faculty of Educational Studies, Universiti Putra Malaysia, Malaysia

Received: October 8, $2010 \quad$ Accepted: April 1,2011 doi:10.5539/ass.v7n9p142

\begin{abstract}
This research examined whether Emotional Intelligence (EI) could be considered as a predictor for mental health. It also aimed to explore the moderating effect of Gender on the relationship between EI and mental health among high school students. The participants in the study included 10th, 11th, and 12th grade students from 8 public high schools in Gorgan City, north of Iran. They were 247 high school students, specifically comprised 124 boys and 123 girls, age ranged between 14 to 17 years old. The research design was an ex post facto and tested for alternative hypotheses. Two valid and reliable instruments were used to assess EI and mental health. Data analysis included frequencies, percentages, mean scores, simple regressions and moderated regressions. The result demonstrated that mental health could be influenced by EI. In addition, gender was a significant moderator for the relationship between EI and mental health.
\end{abstract}

Keywords: Psychology, Education, Emotional intelligence, Mental health, Adolescents

\section{Introduction}

The World Health Organization conceptualized mental health separate from mental ill-health and defined the concept as: "a state of well-being in which the individual realizes his or her own abilities, can cope with the normal stresses of life, can work productively and fruitfully, and is able to make a contribution to his or her own community". (WHO, 2007, p. 1). On a societal level, mental health is perceived as a positive source contributing to asset development individually, socially, and economically (WHO, 2004). Positive mental health is also link to better physical health, increased pro-social behaviors, and participation in less adverse behaviors in adolescence (Resnick, 2000). Better mental health outcomes in adolescents are characterized by greater adaptation in family, society, and school environment, improved quality of life (Hoagwood et al., 1996; USDHHS, 1999). Conversely, poor mental health and well-being (i.e. depression, low self-esteem) during the adolescent years can lead to adolescent health risk behaviors, school failure, physical ill-health, suicide, involvement in juvenile and criminal justice systems, negative life choices, and mental disorders in adulthood (Lewinsohn et al., 1993; Canals, et al., 2002; Trzesniewski et al., 2006; Hjemdal et al., 2007).

There is some evidence that EI development and emotional experiences are helpful for health. Also, there is a significant relationship between awareness of emotional experiences and health. As whole, it seems emotional functions including EI and its components can be used as an instrument in relates with individual mental health. At the same time, many authors and researcher claim and reported that a significant relationship between EI and mental health (Goleman, 1995; Salovey \& Mayer, 1990; Ioannis and Ioannis, 2005). Therefore, the aim of this study was to investigate the relationship of EI with mental health. In addition, the current study sought to provide more evidence pertaining to the relationship of EI with psychological health condition. Particularly, this study examined whether EI affected the psychological aspect of health functioning.

Emotional intelligence (EI) was originally recognized as having its roots in the concept of social intelligence (Salovey \& Mayer, 1990; Goleman, 1995). Later, researches provided evidence that the two concepts actually represent interrelated components of the same construct (Salovey \& Mayer, 1990; Bar-On et al., 2003; Lane \& McRae, 2004). Consequently, this broad construct was accurately referred to as "emotional-social intelligence" 
(Bar-On, 2006). Based on historical reference, traits such as the capacity to navigate through and to adapt to one's own environment and the possession of social and emotional "skills" are important not only to basic survival, but have implications in the areas of relationships, work, school, and emotional and mental health (Goleman, 1995; Salovey \& Mayer, 1990).

Conceptual models appearing most frequently in the literature include the Salovey-Mayer model (Mayer \& Salovey, 1997), the Goleman model (1998b), and the Bar-On model (2000). The above models and researchers revealed the implications of EI on mental and emotional health, relationships, self-motivation, adaptability, and problem solving, suggesting that without these skills or abilities, individuals will not be as successful. Elias et al., (2002), Bar-On (2006) and others have also claimed that the skills of Social Emotional Learning Model (SEL) and emotional-social intelligence can be taught and are generalizable across situations (i.e., work, school, social, etc.). It has been suggested that introduction of these skills may positively impact on school climate, by infusing interventions into multiple subject areas and encouraging prosocial behaviour, thus creating a more positive climate (Graczyk et al., 2000).

The popularity of the concept of EI for the past decades has led researchers to examine its potency in various areas of human functioning. Among the areas with the strongest connections to EI is developmental, educational, clinical and counselling, industrial and organizational psychology. Hence, characteristic or ability EI were related to physical and mental health (Ioannis \& Ioannis, 2005), life satisfaction and well-being (Martinez-Pons, 1997; Palmer et al., 2002), life success (Bar-On, 2001; Goleman, 1995), vocational stress (Bar-On et al., 2000; Nikolaou \& Tsaousis, 2002; Slaski \& Cartwright, 2002), job success and performance (Dulewicz \& Higgs, 1998; Vakola et al., 2004), individual performance (Lam \& Kirby, 2002), interpersonal relationships (Fitness, 2001; Flury \& Ickes, 2001), academic achievement (Van der Zee et al., 2002; Parker et al., 2004) leadership (Palmer et al., 2000), etc.

Taylor (2001) argued that if you are emotionally intelligent then you can cope better with life's challenges and control your emotions more effectively, both of which contribute to good mental and physical health. They stated that EI was strongly correlated with both, physical and psychological health. Furthermore, Salovey (2001) suggested that emotions' manifestation has a positive impact on physical health when people are confident about their abilities to regulate them. He proposed that the best way of dealing with the expression of our feelings in terms of our health is through the rule of "golden mean". "We may need to express negative feelings, but in a way that is neither mean spirited nor stifled" (p. 170). Moreover, Dulewicz, et al., (2003), examined the role emotional self-management such as stress, distress, morale and poor quality of working life play in everyday life.

Emotional intelligence research has provided evidence to suggest that differences exist in emotional intelligence between men and women. In a study on a sample of 13 males and 19 females, Mandell and Pherwani (2003) found a statistically significant difference in emotional intelligence between male and female managers, with females exhibiting higher emotional intelligence. Research by Mayer and Geher in 1996, and again by Mayer, Caruso, and Salovey, and more recently by Mandell and Pherwani (2003), concluded that women may score higher on measures of emotional intelligence than men, both in professional and personal settings (Brown \& Stys, 2004). Liang (2007) investigated the relationship between gender and emotional intelligence on a sample of 100 college and university faculty members in Taiwan. Each of the 100 subjects completed the Nelson and Low Emotional Skills Assessment Process. Liang found that, for this sample of Taiwanese college and university faculty members, no significant difference existed in emotional intelligence between males and females.

\section{Method}

\subsection{Participants}

The participants in the study included male and female adolescents. The sample was made up of two hundred and forty seven Iranian high school students (124 boys and 123 girls) in Gorgan city, north of Iran. Their ages ranged from $15-17$ years old. They were selected as respondents in this study during the 2009/2010 academic year via cluster sampling, and their participation was voluntary and anonymous.

\subsection{Measures}

Two instruments were used for data gathering including:

2.2.1 Emotional Intelligence Inventory, Youth Version (EQ-i YV, Bar-On and Parker, 2000); Utilized to measure emotional intelligence, the Bar-On Emotional Quotient Inventory: Youth Version (EQ-i: YV) was developed by Reuven Bar-On, Ph.D. and James D.A. Parker, Ph.D., and published by Multi-Health Systems, Inc., in 2000. The EQ-i: YV was developed to measure emotional intelligence in adolescent populations, based on the theoretical basis of the Bar-On model of social and emotional intelligence. This 60-item inventory is a self-report 
instrument designed to measure emotional intelligence in young people aged 7 to 18 years. The instrument measures a cross-section of abilities and competencies that constitute the core features of emotional intelligence. Responses are invited on a four-point scale ranging from "very seldom true of me" to "very often true of me". For this study the simple Likert method (1-2-3-4) was chosen. The measure yields an overall EI score (range $0-240)$. The scale has a Cronbach alpha of 0.74 .

2.2.2 General Health Questionnaire (GHQ-28, Goldberg, 1972; Goldberg \& Williams, 1998). In 1972, Goldberg developed a simple questionnaire, which has been the most widely used instrument for detecting non-psychotic psychiatric "Cases", i.e. the General Health Questionnaire (GHQ). The GHQ is a self-administered screening questionnaire used to diagnose psychiatric disorders both in primary care and in the community. The main benefits of GHQ are it is easy to administer, brief, and objective. Several versions of GHQ are available: a 60 -item version, and shorter versions (comprising 30, 28 and 12 items). The 28-item version (GHQ-28) developed by Goldberg and Hillier (1979) was constructed on a different basis when compared with the other versions. Responses were anchored on a four-point scale ranging from "less than usual", to "much more than usual". Of the four possible ways of scoring this instrument (Goldberg \& Williams, 1998), this study chose the simple Likert method (0-1-2-3). The measure yielded an overall health scores (range 0-84) and was composed of four subscales described as somatic symptoms, anxiety and insomnia, social dysfunction and depression. High scores indicated high levels of psychological strain. The measure was found to have an acceptable level of internal consistency reliability (alpha $=0.92$ ). High scores on this scale indicated poor general health.

\section{Results}

To fulfil the main objective of the present study, the obtained data were subjected to a number of statistical analyses by using statistical package for social sciences (SPSS 17.0). Although the analyses most pertinent to the objectives of the study were multiple and moderated regression analyses, descriptive statistics was also reported.

\subsection{Descriptive statistics}

Table 1 presents the mean and standard deviations for all the observed variables. Descriptive statistics was executed to determine the pattern of score distribution. A perusal of Table 1 reveals that the mean score for EI variable is 2.90 with the standard deviation of .29, and the mean score for GHQ is .91 with the SD of .43, (See Table 1).

SRA was computed to assess the strength of relationship between the dependent variable and the independent variables. SRA provides an opportunity with little ambiguity to assess the importance of the predictor to the overall relationship. The results of the regression analysis for the dependent variable (total mental health) are presented in Table 2. The regression analysis proved that EI is a significant predictor for total mental health. Table 2 shows that $\mathrm{R}=.598, \mathrm{R}^{2}=.357$, adjusted $\mathrm{R}^{2}=.354$ and $\{\mathrm{F}(1,245)=136.099, \mathrm{P}<.05\} . \mathrm{R}^{2}$ means that $35.7 \%$ of the variance in mental health increase is explained by EI. Based on the values reported in the variable, the beta coefficient for EI was -.598. This means that EI makes the strongest contribution to explain total mental health. It suggests that an increment of one standard deviation in EI is followed by -.598 standard deviation increase in mental health (See Table 2).

\subsection{Moderated Regression Analysis (MRA)}

MRA was employed in examining the effects of moderating variable (gender) on the relationship between EI and mental health. MRA involved two steps. First, two regression equations were formulated; the first equation included only the first- order.

$\mathrm{Y}=\mathrm{a}+\mathrm{b}_{1} \mathrm{X}+\mathrm{b}_{2} \mathrm{Z}_{+} \mathrm{e}$

$\mathrm{Y}$ is a dependent variable, $\mathrm{X}$ is a predictor and $\mathrm{Z}$ is the second binary predictor that is hypothesised to be a moderator, where $a$ is the least-squares estimate of the intercept, $b_{1}$ is the least-squares estimate of the population regression coefficient for $\mathrm{X}, \mathrm{b}_{2}$ is the least-squares estimate of the population regression coefficient for $\mathrm{Z}$, and $\mathrm{e}$ is the residual term.

The second model included the first-order effects as well as a product term including the moderating variable.

$\mathrm{Y}=\mathrm{a}+\mathrm{b}_{1} \mathrm{X}+\mathrm{b}_{2} \mathrm{Z}_{+} \mathrm{b}_{3} \mathrm{X}^{*} \mathrm{Z}+\mathrm{e}$

Where, $b_{3}$ in the sample was based leased-squares estimations of the population regression for the product term. As noted by Aguinis (2004), one way to examine that the moderator variable has statistically significant effects was to compare the $\mathrm{R}^{2}$ form model $\mathrm{Z}$ (i. e. including the first-order effect only). The difference between these two coefficients of determination (i. e. $\mathrm{R}^{2}$ ) indicated the proportion of variance in $\mathrm{Y}$, explained by the interaction effect above and beyond the proportion of variance explained by the first-order effects. Therefore, the change of 
$\mathrm{R}^{2}$ seemed to be the most frequently used way to examine the magnitude of the moderating effect (Aguinis, 2004).

In this research, the product term was gender. The following are the two equations that derived from the regression procedures by entering the independent variables and product term block by block in order to create two models.

Table 3 shows that for Model $1, \mathrm{R}=.598, \mathrm{R}^{2}=.357$, adjusted $\mathrm{R}^{2}=354$ and $\{\mathrm{F}(1,245)=136.099, \mathrm{P}<.05\} . \mathrm{R}^{2}$ means that $35.7 \%$ of the variance in mental health increase is explained by EI. Model 1 did not include gender as the product term and, thus, ignored a possible moderating effect. To find out the existence of a potential moderating effect on the EI and mental health relationship, we need to interpret Model 2 in Table 3.

Model 2 in Table 3 demonstrates the results after the product term had been included in the equation. As shown in Table 3, the addition of the product term resulted in an $\mathrm{R}^{2}$ change of .012 , $\mathrm{F}$ change $(1,244)=4.786$, Sig. $\mathrm{F}$ change $=.030$ at the $\mathrm{p}<.05$. The results supported the presence of a moderating effect. In other words, the inclusion of gender as the moderating variable does explain the variance in mental health. Thus, the result suggested that gender was a moderator on the relationship between EI and mental health.

\section{Discussion}

The results of this study found that EI was significantly and negatively correlated with mental health scores. This finding is in line with previous findings (e.g. Bar-On, 2001; Goleman, 1995; Martinez-Pons, 1997; Palmer et al, 2002; Ioannis \& Ioannis, 2005). The results of the Simple Regression Analyses revealed that EI was a significant predictor for total mental health scores. Therefore, the findings of this study supported a positive effect of EI on students' mental health scores. The overall regression model was successful in explaining approximately $35.7 \%$ of the proportion variance explained in mental health scores. Finally, the findings of the results failed to provide evidence for the hypothesis that gender has a moderating effect on the relationship between EI and mental health. This finding is in line with Mandell and Pherwani, (2003) and contradicts with Liang, (2007).

\section{Conclusion}

The main purpose of the present study was to explain the role of EI on mental health (somatic symptom, anxiety, social dysfunction and depression) in high school students. The present investigation also tried to test the moderating effect of gender on the relationship of EI with mental health. This research found that students' mental health could be predicted by EI. In other words, The R-squared of .357 implied that the predictor variable (EI) explained about $35.7 \%$ of the variance in mental health (dependent variable). The findings also proved that gender did pose moderating effect on the relationship between EI and mental health scales and sub- scales. In other words, The R-squared of .306 implies that the predictor variable (EI) explain about $30.6 \%$ of the variance in the mental health (dependent variable). The findings also proved that gender did pose moderate effect on the relationships between the EI and mental health. These findings suggest that EI is important and should be encouraged in school for the betterment of students' mental health life. Therefore, this information is important to community counsellors, teachers, school counsellors, and parents; all of whom are concerned with both the academic and social-spiritual development of children, and with the climate of children's learning environments.

\section{Acknowledgment}

We thank the administrative officers at all schools involved in this research sampling for providing us information about the students and allowing them to cooperate. We also appreciate the participation of the volunteered high schools students in this research, thus giving way for us to collect the necessary data for the study.

\section{References}

Aguinis, H. (2004). Regression analysis for categorical moderators: The Guilford Press.

Bar-On, R. (1997). The Emotional Intelligence Inventory (EQ-I): Technical Manual. Toronto, Canada: Multi-Health Systems.

Bar-On, R. (2000). Emotional and social intelligence: Insights from the Emotional Quotient Inventory. The handbook of emotional intelligence, 363-388.

Bar-On, R. (2001). Emotional intelligence and self-actualization. In J. Ciarrochi, J.P. Forgas, \& J.D. Mayer (Eds), Emotional intelligence in every day life: A scientific inquiry (pp. 82-97). Philadelphia, PA: Psychology Press.

Bar-On, R. (2006). The Bar-On model of emotional-social intelligence (ESI). Psicothema, 18, 13-25. 
Bar-On, R., Brown, J. M., Kirkcaldy, B. D., \& Thome, E. P. (2000). Emotional expression and implications for occupational stress; an application of the Emotional Quotient Inventory (EQ-i). Personality and Individual Differences, $28 \quad 1107-1118$. doi:10.1016/S0191-8869(99)00160-9, http://dx.doi.org/10.1016/S0191-8869(99)00160-9

Bar-On, R., \& Parker, J. D. A. (2000). The handbook of emotional intelligence: Theory, development, assessment, and application at home, school, and in the workplace. San Francisco, CA: Jossey-Bass.

Bar-On, R., \& Parker, J. D. A. (2000b). Bar-On Emotional Quotient Inventory: Youth Version. Technical Manual. North Tonawanda, NY: Multi-Health Systems. Inc.

Bar-On, R., Tranel, D., Denburg, N., \& Bechara, A. (2003). Exploring the neurological substrate of emotional and social intelligence. Brain, 126(8), 1790. doi:10.1093/brain/awg177, http://dx.doi.org/10.1093/brain/awg177

Brown, S., \& Stys, Y. (2004). A Review of the Emotional Intelligence Litereture and Implications for Correlations. Research Branch-Correctional Serviece of Canada.

Canals, J., Domènech-Llaberia, E., Fernández-Ballart, J., \& Martí-Henneberg, C. (2002). Predictors of depression at eighteen. European Child \& Adolescent Psychiatry, 11(5), 226-233. doi:10.1007/s00787-002-0286-y, http://dx.doi.org/10.1007/s00787-002-0286-y

Dulewicz, v., \& Higgs, M. (1998). Emotional intelligence: Can it be measured reliably and validly using competency data. Competency, 6, 1-15.

Dulewicz, v., Higgs, M., \& Slaski, M. (2003). Measuring emotional intelligence: content, construct, and criterionrelated validity. Journal of Managerial Psychology, 18, 405-420.

Fitness, J. (2001). Emotional intelligence and intimate relationships. In J. Ciarrochi, J.P. Forgas, \& J.D. Mayer (Eds), Emotional intelligence in every day life: A scientific inquiry (pp. 98-112). Philadelphia, PA: Psychology Press.

Flury, J., \& Ickes, W. (2001). Emotional intelligence and empathetic accuracy. In J. Ciarrochi, J.P. Forgas, \& J.D. Mayer (Eds), Emotional intelligence in every day life: A scientific inquiry (pp. 113-132). Philadelphia, PA: Psychology Press.

Goldberg, D. P. (1972). The detection of psychiatric illness by questionnaire. London: Oxford University Press.

Goldberg, D. P., \& Hillier, V. F. (1979). A scaled version of the General Health Questionnaire. Psychological Medicine, 9(1), 139-145. doi:10.1017/S0033291700021644, http://dx.doi.org/10.1017/S0033291700021644

Goldberg, D. P., \& Williams, P. (1998). A user's guide to the General Health Questionnaire. Windsor: NFER-Nelson.

Goleman, D. (1995). Emotional intelligence: Why it can matter more than IQ. New York: Bantam.

Goleman, D. (1998b). Working with emotional intelligence. New York: Bantam.

Graczyk, P. A., Matjasko, J. L., Weissberg, R. P., Greenberg, M. T., Elias, M. J., \& Zins, J. E. (2000). The role of the collaborative to advance social and emotional learning (CASEL) in supporting the implementation of quality school-based prevention programs. Journal of Educational and Psychological Consultation, 11(1), 3-6. doi:10.1207/S1532768XJEPC1101_2, http://dx.doi.org/10.1207/S1532768XJEPC1101_2

Hjemdal, O., Aune, T., Reinfjell, T., Stiles, T. C., \& Friborg, O. (2007). Resilience as a predictor of depressive symptoms: A correlational study with young adolescents. Clinical Child Psychology and Psychiatry, 12(1), 91-104. doi:10.1177/1359104507071062, http://dx.doi.org/10.1177/1359104507071062

Hoagwood, K., Jensen, P. S., Petti, T., \& Burns, B. J. (1996). Outcomes of mental healthcare for children and adolescents: A comprehensive conceptual model. Journal of the American Academy of Child \& Adolescent Psychiatry, $\quad 35(8), \quad 1055 \quad-1063 . \quad$ doi:10.1097/00004583-199608000-00017, http://dx.doi.org/10.1097/00004583-199608000-00017

Ioannis, T., \& Ioannis, N. (2005). Exploring the relationship of emotional intelligence with physical and psychological functioning. Stress and Health, 21, 77-86. doi:10.1002/smi.1042, http://dx.doi.org/10.1002/smi.1042

Lam, L., \& Kirby, S. (2002). Is emotional intelligence an advantage? An exploration of the impact of emotional and general intelligence on individual performance. The Journal of Social Psychology, 142(1), 133-143. doi:10.1080/00224540209603891, http://dx.doi.org/10.1080/00224540209603891 
Lane, R., \& McRae, K. (2004). Neural substrates of conscious emotional experience: a cognitive neuroscientific perspective. Consciousness, emotional self-regulation and the brain, 87-122.

Lewinsohn, P. M., Hops, H., Roberts, R. E., Seeley, J. R., \& Andrews, J. A. (1993). Adolescent psychopathology: I. prevalence and incidence of depression and other DSM-III-R disorders in high school students. Journal of Abnormal Psychology, 102(1), 133-144. doi:10.1037/0021-843X.102.1.133, http://dx.doi.org/10.1037/0021-843X.102.1.133

Liang, Y. (2007). The relationship between personality type and emotional intelligence in a sample of college and university faculty in Taiwan. Unpublished Ed.D, University - Kingsville, Texas A\&M.

Mandell, B., \& Pherwani, S. (2003). Relationship between emotional intelligence and transformational leadership style: A gender comparison. Journal of Business and Psychology, 17(3), 387-404. doi:10.1023/A:1022816409059, http://dx.doi.org/10.1023/A:1022816409059

Martinez-Pons, M. (1997). The relation of emotional intelligence with selected areas of personal functioning. Imagination, Cognition and Personality, 17, 3-13. doi:10.2190/68VD-DFXB-K5AW-PQAY, http://dx.doi.org/10.2190/68VD-DFXB-K5AW-PQAY

Mayer, J. D., \& Salovey, P. (1997). What is emotional intelligence? In Salovey, P. and Sluyter, D. J. (Eds.), Emotional Development and Emotional Intelligence (pp. 3-31). New York: Basic Books.

Nikolaou, I., \& Tsaousis, I. (2002). Emotional intelligence in the workplace: Exploring its effects on occupational stress and organizational commitment. International Journal of Organizational Analysis, 10(4), 327-342. doi:10.1108/eb028956, http://dx.doi.org/10.1108/eb028956

Palmer, B., Donalson, C., \& Tough, C. (2002). Emotional intelligence and life satisfaction Personality and Individual Differences 33, 1091-1100. doi:10.1016/S0191-8869(01)00215-X, http://dx.doi.org/10.1016/S0191-8869(01)00215-X

Parker, J. D. A., Summerfeldt, L. J., Hogan, M. J., \& Majeski, S. A. (2004). Emotional intelligence and academic success: Examining the transition from high school to university. Personality and Individual Differences, 36, 163-172. doi:10.1016/S0191-8869(03)00076-X, http://dx.doi.org/10.1016/S0191-8869(03)00076-X

Resnick, M. D. (2000). Protective factors, resiliency, and healthy youth development. Adolescent Medicine: State of the Art Reviews, 11(1), 157-164.

Salovey, P. (2001). Applied emotional intelligence: Regulating emotions to become healthy, wealthy, and wise. In J. Ciarrochi, \& J.P. Forgas (Eds), Emotional intelligence in everyday life: A scientific enquiry (pp. 168-184). PhiladelphiaPA: Taylor \& Francis.

Salovey, P., \& Mayer, J. D. (1990). Emotional intelligence. Imagination, Cognition and Personality, 9, 185-211.

Slaski, M., \& Cartwright, S. (2002). Health, performance and emotional intelligence: an exploratory study of retail managers. Stress and Health, 18(2), 63-68. doi:10.1002/smi.926, http://dx.doi.org/10.1002/smi.926

Taylor, G. J. (2001). Low emotional intelligence and mental illness. In J. Ciarrochi, \& J.P. Forgas (Eds), Emotional intelligence in everyday life: A scientific enquiry (pp. 67-81). Philadelphia, PA: Taylor \& Francis.

Thorndike, E. L. (1920). Intelligence and its uses. Harper's Magazine, 140, 227-235.

Trzesniewski, K. H., Donnellan, M. B., Moffitt, T. E., Robins, R. W., Poulton, R., \& Caspi, A. (2006). Low self-esteem during adolescence predicts poor health, criminal behavior, and limited economic prospects during adulthood. Developmental Psychology, 42(2), 381-390. doi:10.1037/0012-1649.42.2.381, http://dx.doi.org/10.1037/0012-1649.42.2.381

US Department of Health and Human Services (1999). Mental health: A report of the surgeon general. Rockville, MD: US Department of Health and Human Services, Substance Abuse and Mental Health Services Administration, Center for Mental Health Services National Institutes of Health, National Institute of Mental Health.

Vakola, M., Tsaousis, I., \& Nikolaou, I. (2004). The effects of emotional intelligence and personality variables on attitudes toward organizational change. Journal of Managerial Psychology, 19, 88-110. doi:10.1108/02683940410526082, http://dx.doi.org/10.1108/02683940410526082

Van der Zee, K., Thijs, M., \& Schakel, L. (2002). The relationship of emotional intelligence with academic intelligence and the Big Five. European Journal of Personality, 16, 103-125. doi:10.1002/per.434, http://dx.doi.org/10.1002/per.434 
World Health Organization (2004). Promoting mental health: Concepts, emerging, practice Geneva: Department of Mental Health and Substance Abuse. [Online] Available: http://www.aihi.unimelb.edu.au/pdf/publications/promotingMentalHealth.pdf

World Health Organization. (2007). Strengthening mental health promotion. (Fact Sheet No. 220). [Online] Available: http://www.who.int/mediacentre/factsheets/fs220/en/

Table 1. Descriptive Statistics of the Independent \& Dependent Variable

\begin{tabular}{lccccc}
\hline Variables & $\mathbf{N}$ & Minimum & Maximum & Mean & $\begin{array}{c}\text { Std. } \\
\text { Deviation }\end{array}$ \\
\hline \hline $\begin{array}{l}\text { Emotional Intelligence } \\
\text { (EI) }\end{array}$ & 247 & 2.15 & 3.67 & 2.9028 & .29031 \\
Total Mental Health & 247 & .04 & 2.04 & .9110 & .42770 \\
\hline \hline
\end{tabular}

Table 2. Simple Regression Analysis of the Total Mental Health

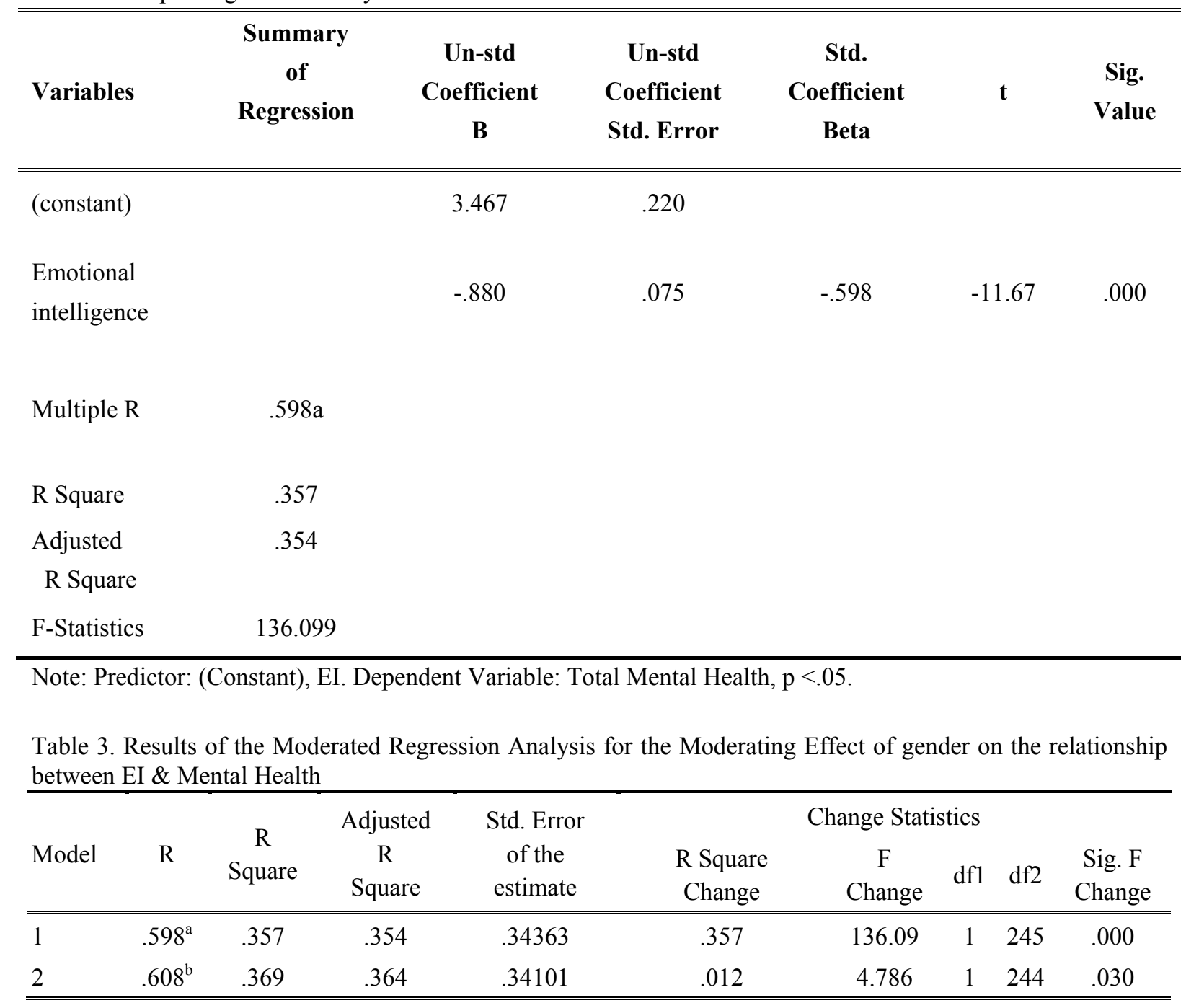

Note: Predictors step 1: Total EI, Predictors step 2: Total EI, Students Gender, * $\mathrm{p}<.05$. 